\title{
Prospective randomized controlled trial of an injectable esophageal prosthesis versus a sham procedure for endoscopic treatment of gastroesophageal reflux disease
}

\author{
Paul Fockens - Lawrence Cohen • Steven A. Edmundowicz $\cdot$ Kenneth Binmoeller • \\ Richard I. Rothstein · Daniel Smith • Edward Lin · Nicholas Nickl • Bergein Overholt • \\ Peter J. Kahrilas • Nimish Vakil • Ayman M. Abdel Aziz Hassan • Glen A. Lehman
}

Received: 8 August 2009/Accepted: 9 November 2009/Published online: 3 March 2010

(C) The Author(s) 2010. This article is published with open access at Springerlink.com

\begin{abstract}
Background This study aimed to assess whether endoscopic implantation of an injectable esophageal prosthesis, the Gatekeeper Reflux Repair System (GK), is a safe and effective therapy for controlling gastroesophageal reflux disease (GERD).

Methods A prospective, randomized, sham-controlled, single-blinded, international multicenter study planned final enrollment of 204 patients in three groups: up to 60 lead-in, $96 \mathrm{GK}$, and 48 sham patients. The sham patients were allowed to cross over to the GK treatment arm or exit the study at 6 months. The primary end points were (1)
\end{abstract}

\section{P. Fockens}

Academic Medical Center, University of Amsterdam,

P.O. Box 22700, 1100 DE Amsterdam, the Netherlands

L. Cohen

The Mount Sinai School of Medicine, New York, NY, USA

\section{S. A. Edmundowicz}

Washington University School of Medicine, 660 S. Euclid Ave.

Campus Box 8124, St. Louis, MO 63110, USA

e-mail: sedmundo@wust1.edu

\section{K. Binmoeller}

California Pacific Medical Center, San Francisco, CA, USA

\section{R. I. Rothstein}

Dartmouth Medical School, Dartmouth Hitchcock Medical

Center, 1 Medical Center Drive, Lebanon, NH 03756, USA

e-mail: Richard.rothstein@darmouth.edu

\section{Smith · E. Lin}

Emory University, 2004 Ridgewood Dr NE, Atlanta, GA 30322, USA

N. Nickl

University of Kentucky Medical Center, Lexington, KY, USA reduction in serious device- and procedure-related adverse device effects compared with a surgical composite complication rate and (2) reduction in heartburn symptoms 6 months after the GK procedure compared with the sham procedure. The secondary end point was improved esophageal $\mathrm{pH}$ (total time $\mathrm{pH}$ was <4) 6 months after the GK procedure compared with baseline.

Results A planned interim analysis was performed after 143 patients were enrolled ( 25 lead-in, $75 \mathrm{GK}$, and 43 sham patients), and the GK study was terminated early due to lack of compelling efficacy data. Four reported serious adverse events had occurred ( 2 perforations, 1 pulmonary

\author{
B. Overholt \\ Gastrointestinal Associates, Knoxville, TN, USA \\ P. J. Kahrilas \\ Division of Gastroenterology, Feinberg School of Medicine, \\ Northwestern University, 676 N. Saint Clair St., Suite 1400, \\ Chicago, IL 60611-2951, USA \\ e-mail: p-kahrilas@northwestern.edu \\ N. Vakil \\ University of Wisconsin School of Medicine and Public Health, \\ Madison, WI, USA
}
A. M. Abdel Aziz Hassan
Division of Gastroenterology and Hepatology, Indiana
University Medical Center, 550 N. University Boulevard,
Suite 4100, Indianapolis, IN 46202, USA
G. A. Lehman $(\bowtie)$
Division of Gastroenterology and Hepatology, Indiana
University Medical Center, 550 N. University Boulevard,
UH 4100, Indianapolis, IN 46202, USA
e-mail: glehman@iupui.edu 
infiltrate related to a perforation, and 1 severe chest pain) at termination of the study with no mortality or long-term sequelae. Heartburn symptoms had improved significantly at 6 months compared with baseline in the GK group $(p<0.0001)$ and the sham group $(p<0.0001)$, but no significant between-group difference in improvement was observed $(p=0.146)$. Esophageal acid exposure had improved significantly at 6 months compared with baseline in the GK group $(p=0.021)$ and the sham group $(p=0.003)$, but no significant between-group difference in improvement was observed $(p=0.27)$.

Conclusions The GK procedure was associated with some serious but infrequent complications. No statistically significant difference in outcomes was observed between the treatment and control groups at 6 months compared with baseline.

Keywords Gastroesophageal reflux disease . Gatekeeper - GORD/GERD - Sham procedure

Symptoms associated with gastroesophageal reflux disease (GERD) are common, with an incidence of approximately $20 \%$ in the general population [1]. Findings show that GERD has a substantial impact on patient quality of life and use of health care resources [2]. The pathophysiology of GERD is multifactorial and often includes low resting pressure of the lower esophageal sphincter (LES) and occurrence of transient LES relaxations. This episodically exposes the esophageal body to gastric acid and enzymes [3]. Usually, GERD manifests as heartburn and regurgitation, predisposing the patient to the development of esophagitis, Barrett's metaplasia, and esophageal adenocarcinoma [4].

The current therapy for GERD begins with lifestyle changes and medical treatment, which prove to be adequate or effective for more than $90 \%$ of patients. Such therapy usually must be maintained long term because the rate for recurrence of symptoms is as high as $90 \%$ after cessation of medication. In addition, long-term drug therapy is associated with issues of cost, compliance, and long-term safety [5].

Patients who do not tolerate medication, respond inadequately to medication, or wish to avoid life-long drug therapy may be considered as candidates for surgery. Such surgery necessitates general anesthesia, has a mortality rate of approximately $0.2 \%$, and can be associated with additional morbidity including dysphagia, gas-bloat syndrome, and postprandial fullness [6].

Over the past few years, several endoscopic therapies have been proposed for the treatment of GERD. These minimally invasive procedures use three different approaches in an attempt to improve the antireflux barrier function: (1) injection of filler materials into the LES and cardia [7-9], (2) delivery of radiofrequency energy to the LES and cardia [10], and (3) creation of gastroplications [11, 12]. Multiple other techniques such as the His-Wiz infrasphincteric plicator [13], use of magnets to augment the esophageal sphincter [14], or implantation of an on-demand microstimulator into the LES to increase LES pressure [15] are under study. These endoluminal techniques may provide an alternative to long-term maintenance therapy with proton pump inhibitors (PPI) or surgery.

The Gatekeeper Reflux Repair System (Medtronic, Inc., Shoreview, MN, USA) offers an injectable technique that uses polyacrylonitrile-based hydrogel prostheses placed into the esophageal submucosal space at the level of the LES to prevent reflux. The procedure is performed endoscopically on an outpatient basis. The current study aimed to compare esophageal submucosal implantation of a hydrogel prosthesis (Gatekeeper Reflux Repair System) and a sham procedure in terms of therapeutic efficacy and safety.

\section{Methods}

\section{Study objectives}

The primary safety end point was reduction in serious device- and procedure-related adverse device effects compared with a surgical procedure composite complication rate of $15 \%$. The primary efficacy end point was reduction in heartburn symptoms (calculated using the first 9 scales from the GERD-HRQL [health-related quality of life] questionnaire) 6 months after the procedure compared with the control group. The secondary efficacy end point was improved esophageal $\mathrm{pH}$, defined as the total percentage of time that $\mathrm{pH}$ was lower than 4 at 6 months after the Gatekeeper procedure compared with baseline.

\section{Study design}

The Gatekeeper trial was a prospective, randomized, shamcontrolled, single-blinded, international, multicenter study. Participants were recruited from 11 centers (10 in the United States and 1 in Europe). The inclusion and exclusion criteria are presented in Table 1 . The study was approved by the investigational review board or the scientific and ethical committee for all the study sites, and all the patients were provided written informed consent before enrollment. During the initial training of investigators (all treated with Gatekeeper prostheses), 25 patients were treated as lead-ins. The lead-in patients met the same eligibility criteria and underwent the same pre- and postprocedure evaluations as the randomized patients. They were, however, not blinded to their therapy, so they were not included in the efficacy analysis. 
Table 1 Inclusion and exclusion criteria

\begin{tabular}{|c|c|}
\hline Inclusion criteria & Exclusion criteria \\
\hline $\begin{array}{l}\text { Age } \geq 18 \text { years old and typical persistent GERD } \\
\text { symptoms (heartburn, regurgitation, or both). All } \\
\text { patients showed symptomatic improvement with PPI } \\
\text { and wanted to discontinue their GERD medications }\end{array}$ & $\begin{array}{l}\text { Dysphagia } \\
\text { Morbid obesity (BMI }>35 \mathrm{~kg} / \mathrm{m}^{2} \text { ) } \\
\text { Severe esophagitis (grade C or D LA classification) }\end{array}$ \\
\hline $\begin{array}{l}\text { Baseline GERD-HRQL heartburn score of } \leq 11 \text { on PPI } \\
\text { and } \geq 20 \text { off PPI (all GERD-related drugs were } \\
\text { stopped for a minimum of } 7 \text { days minimum before } \\
\text { completion of the off-medication GERD-HRQL } \\
\text { questionnaire) }\end{array}$ & $\begin{array}{l}\text { Previous esophagogastric surgery, antireflux procedures, or } \\
\text { gastroesophageal or gastric cancer } \\
\text { Hiatus hernia }>3 \mathrm{~cm} \\
\text { Barrett's esophagus }>2 \mathrm{~cm}\end{array}$ \\
\hline $\begin{array}{l}\text { Pathologic esophageal acid exposure at } \mathrm{pH} \text { testing using } \\
\text { the Bravo } \mathrm{pH} \text { test (baseline } 24-\mathrm{h} \mathrm{pH}, \geq 4 \% \text { of the time } \\
\text { with a } \mathrm{pH} \leq 4.0 \text { ); a standard meal consisting of a } \\
\text { hamburger, cheeseburger or chicken burger, French } \\
\text { fries, and a milkshake was consumed within each } 24-\mathrm{h} \\
\text { period of the } 48-\mathrm{h} \text { pH monitoring }\end{array}$ & $\begin{array}{l}\text { Ineffective esophageal motility (defined as amplitudes of esophageal } \\
\text { peristalsis of }<30 \mathrm{mmHg}>50 \% \text { of the time) } \\
\text { Esophageal or gastric varices } \\
\text { Esophageal strictures } \\
\text { Increased anesthesia risk (ASA Physical Status Classification } 3 \text { or } 4 \text { ) } \\
\text { Immunocompromised status }\end{array}$ \\
\hline $\begin{array}{l}\text { A negative pregnancy test for females of childbearing } \\
\text { potential within } 1 \text { week before treatment }\end{array}$ & $\begin{array}{l}\text { Stroke or transient ischemic neurologic attach within the } 6 \text { months } \\
\text { before enrollment } \\
\text { A significant gastrointestinal bleed with the } 6 \text { months before } \\
\text { enrollment } \\
\text { Other significant disease that may cause patient noncompliance } \\
\text { Coagulation disorder } \\
\text { Simultaneously participation in another drug or device study }\end{array}$ \\
\hline
\end{tabular}

GERD gastroesophageal reflux disease, $B M I$ body mass index, $H R Q L$ health-related quality of life, $L A$ Los Angeles, $P P I$ proton pump inhibitor, ASA American Society of Anesthesiology

Note: The primary reason for screen failure was due to disqualifying GERD-HRQL scores either off or on PPIs

Patients were randomized to receive Gatekeeper prostheses in the treatment arm or a sham procedure in the control arm of the study. All the patients were asked to continue their current PPI therapy for 2 weeks after the Gatekeeper or sham procedure. After the 2-week period, all the patients were asked to discontinue their PPI therapy. The patients who had persistent symptoms of heartburn or regurgitation (defined as requiring antacid use at least 3 or 4 times per week) were given antireflux medication using the following treatment regimen, which progressed at 1- to 2-week intervals:

1. Unlimited use of antacids of the patient's choice; if symptoms persisted, the patient could take over-thecounter H2-blockers to control symptoms.

2. Prescription H2-blockers (at therapeutic doses) and antacids (as needed).

3. PPIs as needed.

4. PPIs at a therapeutic dose per patient requirement.

The patients in the Gatekeeper arm of the study were implanted initially with four Gatekeeper prostheses. At 3 months, the patients were eligible for retreatment with up to four additional prostheses if symptom control was unsatisfactory (GERD-HRQL $>15$ ). To maintain the blind, the patients in the sham arm of the study were offered re-sham procedures if symptom control was unsatisfactory at 3 months (GERD-HRQL $>15$ ). At 6 months, the patients in the sham arm of the study were allowed to cross over to the Gatekeeper treatment arm or to exit the study. The study design is shown in Fig. 1.

\section{Gatekeeper procedure}

Conscious or deep sedation was administrated according to the standard practices of the study centers for upper gastrointestinal endoscopy. The Gatekeeper procedure used a 16-mm overtube as a conduit for the endoscope and the 2.4-mm-diameter hydrogel delivery system (Fig. 2).The endoscope (contained within the lumen of the overtube) and overtube were passed into the lower esophagus over a guidewire. Once these were in position, suction was applied via the endoscope, which pulled the esophageal wall into a shelf at the end of the overtube.

Next, the injection needle was passed through a second channel in the overtube, and 3-6 $\mathrm{ml}$ of saline was injected into the tissue, which had been stabilized previously in the shelf, creating a tissue bleb in the submucosal space. The injection needle was removed, and the prosthesis delivery system (1-mm-diameter needle, dilator, and 2.4-mmdiameter sheath) was passed through the same channel and advanced into the tissue bleb. The needle assembly and dilator then were removed, leaving the sheath in the 
Fig. 1 At 6 months, the blinding was broken, and the patients in the sham group were given the option to cross over to the Gatekeeper group or exit the study

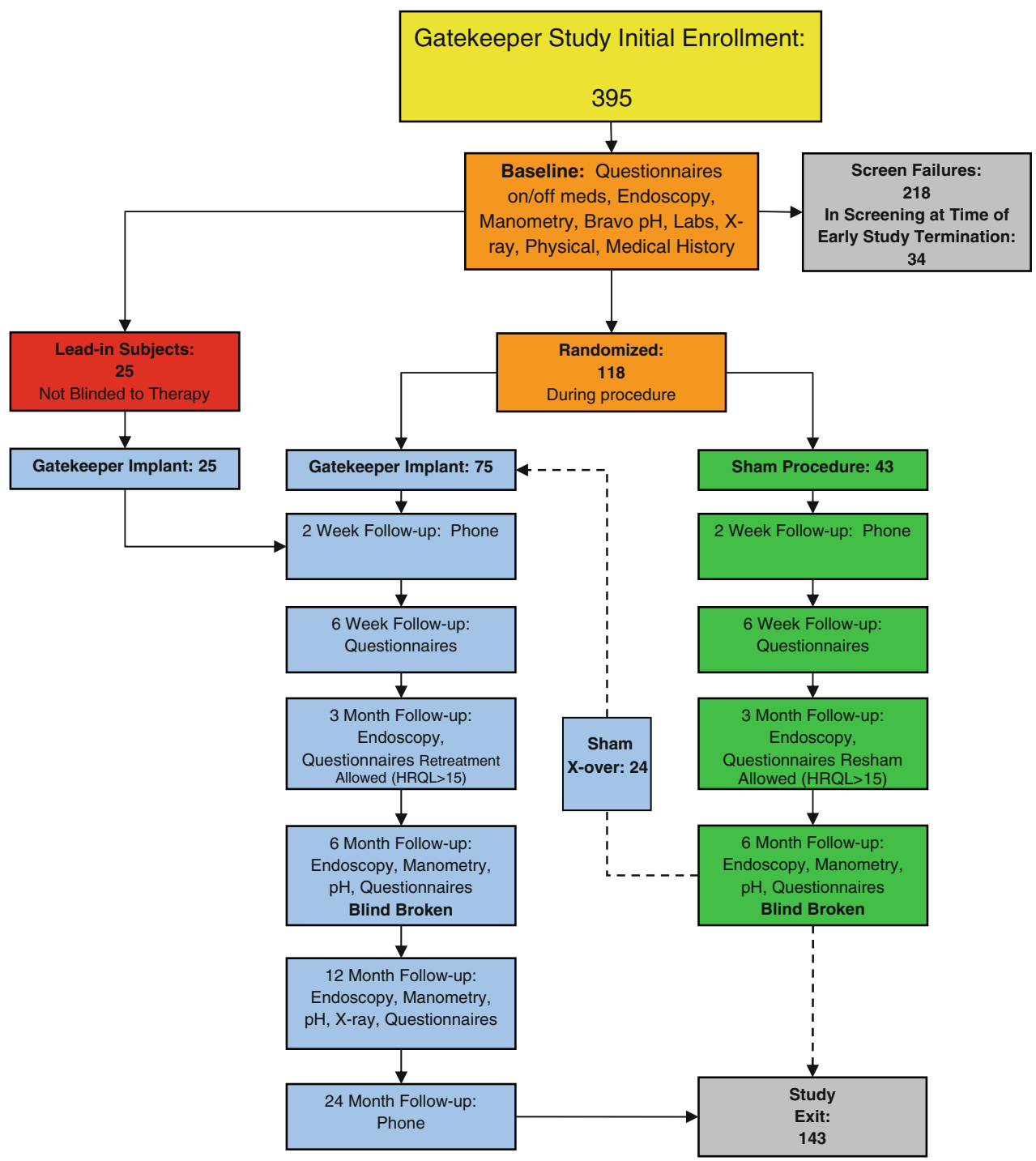

submucosal plane. Next, a dry hydrogel rod 1.0-1.8 $\mathrm{mm}$ in diameter and 10-15 mm long was loaded into the proximal end of the sheath and advanced with a push rod through the sheath into the submucosa. Once the hydrogel was delivered, the push rod and sheath were removed.

For additional deliveries, the overtube and endoscope assembly were rotated approximately $90^{\circ}$, and the process was repeated. Up to four prostheses were implanted during the initial implantation procedure. The complete procedure required approximately $15 \mathrm{~min}$ for the first hydrogel implant and $5 \mathrm{~min}$ for each additional implant. Within $24 \mathrm{~h}$, the hydrogel implants were fully expanded, creating pillow-like mounds in the esophageal wall or cardia submucosa, which bulged into the lumen, thus creating a potential mechanical antireflux barrier.

The sham group underwent upper gastrointestinal endoscopy with conscious or deep sedation. The sham procedure was performed using the same system to simulate delivery, but without injection of saline, advancement of the needle into tissue, or insertion of prostheses.

The patients randomized to the Gatekeeper technique were given intravenous antibiotics during the procedure. The patients randomized to the sham procedure were given $50 \mathrm{ml}$ of normal saline intravenously in place of the antibiotic.

Statistical analysis

The primary efficacy end point, heartburn symptoms, was analyzed using either a two-sample $t$-test or a Wilcoxon rank-sum test, as appropriate. The analysis measured the changes in the HRQL questionnaire heartburn questions between baseline and 6 months, then compared the changes between the study and control groups. The primary safety and efficacy end points had to be met for the study to be considered successful. 

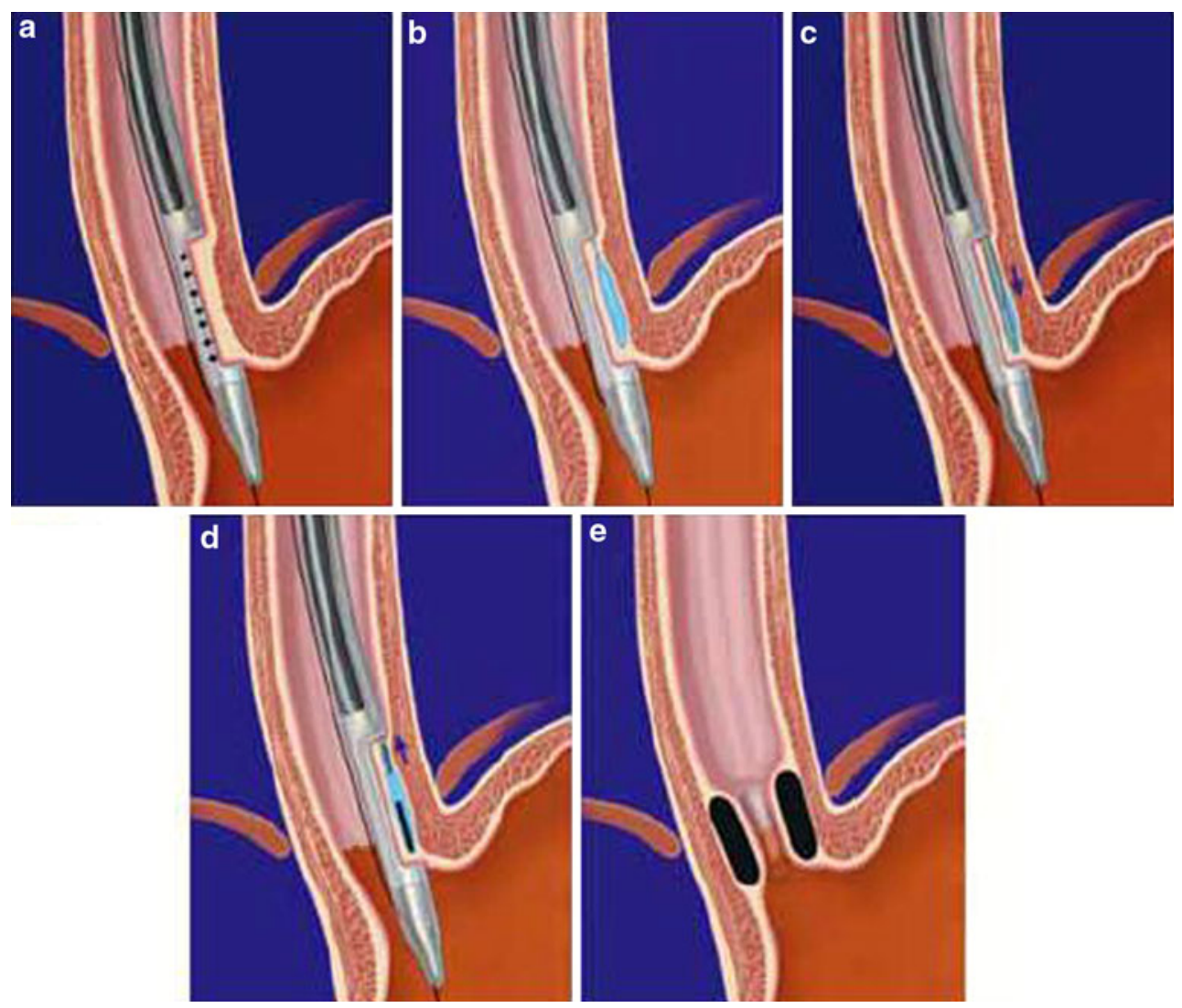

Fig. 2 Gatekeeper procedure. a The esophageal wall is aspirated. b Normal saline is injected into the submucosal layer. c A pocket is created into the submucosal layer. d The prosthesis is implanted in the pocket. e Hydrated prostheses in situ $24 \mathrm{~h}$ after implantation are shown

Improvement in esophageal $\mathrm{pH}$, defined as the total percentage of time that the $\mathrm{pH}$ was less than 4 , was calculated, and other analyses (DeMeester Score, Medical Outcomes Survey Short Form 36 [SF-36], HRQL regurgitation score, and LES pressure) were performed using the same tests as described earlier. Improvement in esophageal $\mathrm{pH}$ was analyzed using the average of two sequential 24-h periods of wireless esophageal $\mathrm{pH}$ monitoring (Bravo $\mathrm{pH}$ Monitoring System; Medtronic Inc.). All $p$ values 0.05 or less were considered statistically significant.

\section{Results}

The study initially enrolled 395 patients from 24 September 2003 to 30 September 2005. A total of 252 patients failed to reach randomization primarily due to disqualifying HRQL scores on or off PPIs. Up to three patients per investigator were planned to be treated as lead-ins. Randomization was planned for 144 patients, with 96 patients to receive the Gatekeeper prosthesis and 48 patients to be in the sham control group. A planned interim analysis was performed after 143 patients were enrolled including 25 lead-ins and 118 randomized (75 Gatekeeper and 43 sham) patients.

The Gatekeeper study was terminated early due to lack of compelling efficacy data. The blinding was broken for all the patients in the study, and no further Gatekeeper implantations were allowed including new randomization, month 3 reimplantations, and cross-over of sham patients to the Gatekeeper arm of the study. All 143 lead-in and randomized patients exited the study. The majority of patients exited the study, with 78 completing the study, 22 electing to have their prostheses removed, 16 withdrawing consent, 12 needing to leave when Medtronic closed the study, 11 lost to follow-up evaluation or lacking efficacy; and 4 having other causes. The study had 6-month followup data available for $51(68 \%)$ of 75 patients in the Gatekeeper group and $26(60 \%)$ of 43 patients in the sham group.

Originally, implant removal was performed for patients who desired it. After removal of the implants from 21 patients resulted in one perforation, one near perforation, and noted discrepancies between the number of prostheses implanted and the number of prostheses explanted, Medtronic reassessed the explantation procedure and prostheses visualization techniques. This led to a change in 
recommendation advising that explantations should be performed only if medically necessary, that a computed tomography (CT) scan should be performed before explantation to identify the number and orientation of prostheses, that only prostheses clearly visible endoscopically should be removed, and that the explantation site should be closed with endoscopic clips. To assess for perforation, nothing by mouth was received and an X-ray using water-soluble contrast was performed after explantation at the discretion of the physician.

For the patients randomized to the Gatekeeper treatment group, the implantation success rate was 92\%. At 3 months, $44.4 \%$ of the implanted randomized patients were retreated with additional implants. Retreatment at 3 months was performed for $40 \%$ of the lead-in patients. At 6 months, 24 patients $(56 \%)$ in the sham group crossed over to the Gatekeeper group, whereas 18 sham patients did not cross over due to early study closure. One sham patient elected to exit the study without crossing over. The Gatekeeper prostheses retention rate, defined as the number of prostheses seen at follow-up endoscopy compared with the initial number implanted, was $73 \%$ at 6 months and $63 \%$ at 12 months respectively.

Primary safety outcome: device- or procedure-related adverse events 6 months after the Gatekeeper procedure

The hypothesis test for adverse events was not performed due to early cessation of the study. At the time of study termination, four device- or procedure-related complications in 124 implanted subjects qualified as serious adverse events. These included esophageal wall perforations in two patients, pulmonary infiltrate related to a perforation in one patient, and severe chest pain in one patient. The overall serious device- or procedure-related adverse event rate was $3.2 \%$, with a $95 \%$ upper confidence limit of $7.2 \%$.

A lead-in patient experienced the first perforation, caused by a Savory guidewire used to pass the overtube during device implantation. Esophageal wall tear occurred, and the patient had an emergency thoracotomy and was admitted to the intensive care unit for 4 days, with an additional 6-day hospital stay. No long-term sequelae occurred.

The second esophageal perforation occurred in the Gatekeeper group after removal of the prostheses via needleknife incision over a prosthesis. The patient had severe retrosternal pain after the procedure. The chest X-ray showed a suspicion of mediastinal air. The esophagogram with water-soluble contrast showed no mediastinal leakage. The patient was admitted to the hospital and treated with antibiotics as well as nothing by mouth. No further intervention was performed. A follow-up chest $\mathrm{X}$-ray showed pulmonary infiltrate and pleural effusion, which were considered the third severe adverse event due to prolongation of the hospital stay. The patient was discharged after 11 days.

The fourth reported serious adverse event was severe substernal chest pain after device implantation. The patient presented to the emergency department the night of the procedure with intense substernal stabbing pain. A chest Xray and a barium esophagram showed no abnormalities. The patient received narcotics for pain and was kept overnight for observation, then released the next day without sequelae.

No serious adverse events occurred in the sham group. Minor complications were reported in all the treatment groups. The most common minor complications were esophageal erosions over the Gatekeeper prostheses, transient nausea and vomiting, dysphagia, chest pain, sore throat, and abdominal pain (Table 2).

Primary efficacy outcome: heartburn symptoms improvement 6 months after the procedure compared with the control group

Compared with baseline, a significant improvement in heartburn symptoms (calculated using the first 9 questions from the GERD-HRQL questionnaire) was observed at 6 months in the Gatekeeper $(p<0.0001)$ and sham $(p<0.0001)$ groups (Table 4). However the improvement in the Gatekeeper group was not better than in the sham group ( $p=0.146$; Table 4). At 12 months, the improvement in heartburn symptoms in the Gatekeeper group continued to be significant ( $p<0.0001$; Table 5).

Secondary efficacy outcomes: improvement in esophageal pH 6 months after the Gatekeeper procedure compared with baseline

The mean esophageal acid exposure times were abnormal for many parameters in both groups at baseline (Table 3). The Gatekeeper and sham groups showed significant improvement in esophageal acid exposure at 6 months compared with baseline, as indicated by Bravo $\mathrm{pH}$ monitoring ( $p=0.021$ and 0.003 , respectively; Table 4). However, the improvement in esophageal acid exposure in the Gatekeeper group was not significantly better than in the sham group at 6 months $(p=0.270$; Table 4$)$.

Additional analysis

Regurgitation symptoms

Compared with baseline, a significant improvement in regurgitation symptoms (calculated using questions 10-15 
Table 2 Total number of device- and procedure-related adverse device effects and total number and percentage of patients with adverse events throughout the study for each study group and for all the study groups combined

\begin{tabular}{|c|c|c|c|c|c|c|c|c|c|c|}
\hline \multirow[t]{2}{*}{ AE category } & \multicolumn{3}{|c|}{ Sham group } & \multicolumn{3}{|c|}{ Gatekeeper group } & \multicolumn{3}{|c|}{ Lead-in group } & \multirow{2}{*}{$\begin{array}{l}\text { Total events } \\
\text { (all) }(n)\end{array}$} \\
\hline & $\begin{array}{l}\text { Events } \\
(n)\end{array}$ & $\begin{array}{l}\text { Patients } \\
(n)\end{array}$ & $\begin{array}{l}\text { Patients } \\
(n=43)\end{array}$ & $\begin{array}{l}\text { Events } \\
(n)\end{array}$ & $\begin{array}{l}\text { Patients } \\
(n)\end{array}$ & $\begin{array}{l}\% \text { of Patients } \\
(n=75)\end{array}$ & $\begin{array}{l}\text { Events } \\
(n)\end{array}$ & $\begin{array}{l}\text { Patients } \\
(n)\end{array}$ & $\begin{array}{l}\% \text { of Patients } \\
(n=25)\end{array}$ & \\
\hline Erosions over prostheses & 26 & 9 & $37.5^{\mathrm{a}}$ & 82 & 23 & 30.7 & 18 & 8 & 32.0 & 126 \\
\hline Sore throat & 9 & 7 & 16.3 & 14 & 13 & 17.3 & 4 & 3 & 12.0 & 27 \\
\hline Nausea/vomiting & 1 & 1 & 2.3 & 15 & 12 & 16.0 & 6 & 6 & 24.0 & 22 \\
\hline Chest pain & 5 & 3 & 7.0 & $20^{\mathrm{b}}$ & 11 & 14.7 & 9 & 6 & 24.0 & 34 \\
\hline Cough & 1 & 1 & 2.3 & 1 & 1 & 1.3 & 0 & 0 & 0.0 & 2 \\
\hline Dysphagia & 3 & 2 & $8.3^{\mathrm{a}}$ & 10 & 7 & 9.3 & 1 & 1 & 4.0 & 14 \\
\hline Epigastric pain & 1 & 1 & 2.3 & 8 & 5 & 6.7 & 2 & 2 & 8.0 & 11 \\
\hline Odynophagia & 1 & 1 & 2.3 & 6 & 5 & 6.7 & 0 & 0 & 0.0 & 7 \\
\hline $\begin{array}{l}\text { Pulmonary infiltrate and } \\
\text { pleural effusion }\end{array}$ & 0 & 0 & 0.0 & $1^{\mathrm{c}}$ & 1 & 1.3 & 0 & 0 & 0.0 & 1 \\
\hline $\begin{array}{l}\text { Prosthesis transmural } \\
\text { migration }\end{array}$ & 1 & 1 & $4.2^{\mathrm{a}}$ & 0 & 0 & 0.0 & 0 & 0 & 0.0 & 1 \\
\hline Hemorrhage & 1 & 1 & 1.96 & 1 & 1 & 1.3 & 0 & 0 & 0.0 & 2 \\
\hline Perforation & 0 & 0 & 0.0 & $1^{\mathrm{c}}$ & 1 & 1.3 & $1^{\mathrm{c}}$ & 1 & 4.0 & 2 \\
\hline Desaturation & 1 & 1 & 2.3 & 1 & 1 & 1.3 & 1 & 1 & 4.0 & 3 \\
\hline Bloating & 0 & 0 & 0.0 & 5 & 4 & 5.3 & 0 & 0 & 0.0 & 5 \\
\hline Hiccough & 0 & 0 & 0.0 & 1 & 1 & 1.3 & 0 & 0 & 0.0 & 1 \\
\hline Headache & 0 & 0 & 0.0 & 2 & 2 & 2.7 & 0 & 0 & 0.0 & 2 \\
\hline $\begin{array}{l}\text { Mouth injury or pain } \\
\text { from overtube }\end{array}$ & 1 & 1 & 2.3 & 1 & 1 & 1.3 & 2 & 2 & 8.0 & 4 \\
\hline Drowsiness & 0 & 0 & 0.0 & 0 & 0 & 0.0 & 1 & 1 & 4.0 & 1 \\
\hline Low-grade fever & 0 & 0 & 0.0 & 0 & 0 & 0.0 & 1 & 1 & 4.0 & 1 \\
\hline $\begin{array}{l}\text { Deformed Anatomy at } \\
\text { GE junction }\end{array}$ & 0 & 0 & 0.0 & 0 & 0 & 0.0 & 2 & 2 & 8.0 & 2 \\
\hline Rash & 0 & 0 & 0.0 & 1 & 1 & 1.3 & 0 & 0 & 0.0 & 1 \\
\hline Misreported AEs ${ }^{\mathrm{d}}$ & 1 & 1 & 2.3 & 1 & 1 & 1.3 & 2 & 1 & 4.0 & 4 \\
\hline Total & 52 & & & 171 & & & 50 & & & 273 \\
\hline
\end{tabular}

$G E$ gastroesophageal, $A E s$ adverse events

${ }^{a}$ The denominator is 24 (the number of Sham patients who crossed over to the Gatekeeper arm)

${ }^{b}$ One patient experienced severe chest pain, which was considered serious

c Considered a serious adverse event

${ }^{\mathrm{d}}$ Four adverse events were reported as device or procedure related but were later adjudicated as not related

from the GERD-HRQL questionnaire) was observed at 6 months in the Gatekeeper $(p<0.0001)$ and sham $(p=0.0003)$ groups (Table 4). However, no difference in improvement between the Gatekeeper and sham groups was observed at 6 months ( $p=0.330$; Table 4$)$. At 12 months, the regurgitation symptoms improvement still was significant in the Gatekeeper group ( $p=0.0003$; Table 5).

\section{Esophageal manometry (LES pressure)}

No statistically significant improvement in LES pressure compared with baseline was observed in the Gatekeeper group at 6 months $(p=0.079)$ and 12 months $(p=0.246)$ (Tables 4,5$)$. The sham group showed a nonsignificant decrease in LES pressure ( $p=0.162$; Table 4$)$. Significant improvement was observed in the Gatekeeper group compared with the sham group at 6 months $(p=0.026$; Table 4$)$.

\section{DeMeester score}

At baseline, the mean DeMeester scores were abnormal, with no significant difference between the groups (Table 3). Significant improvement in the mean DeMeester score compared with baseline was observed in the Gatekeeper $(p=0.001)$ and sham $(p=0.027)$ groups at 6 months (Table 4). However, the Gatekeeper group showed no difference in improvement compared with that of the sham group ( $p=0.573$; Table 4$)$. 
Table 3 Comparison of the two treatment groups at baseline ${ }^{\mathrm{a}}$
$S D$ standard deviation, $B M I$ body mass index, $H R Q L$ healthrelated quality of life, $L E S$ lower esophageal sphincter, $S F$ 36 Medical Outcomes Survey Short Form 36, PCS Physical Component Scale, MCS Mental Component Scale

a The two treatment groups showed no statistically significant difference at baseline except for age and LES resting pressure, which were greater in the sham group

${ }^{b}$ Data were missing for two Gatekeeper patients

\begin{tabular}{|c|c|c|c|}
\hline Variable & Gatekeeper group $(n=75)$ & Sham group $(n=43)$ & $p$ Value \\
\hline \multicolumn{4}{|l|}{ Gender: $n(\%)$} \\
\hline Female & $25(33.3)$ & $18(41.9)$ & \multirow[t]{2}{*}{0.428} \\
\hline Male & $50(66.7)$ & $25(58.1)$ & \\
\hline \multicolumn{4}{|l|}{ Age (years) } \\
\hline Mean $\pm \mathrm{SD}$ & $47.9 \pm 11.59$ & $52.6 \pm 11.80$ & \multirow[t]{2}{*}{0.035} \\
\hline Range & $(23.7-70.3)$ & $(23.5-76)$ & \\
\hline \multicolumn{4}{|l|}{ BMI } \\
\hline Mean $\pm \mathrm{SD}$ & $27.8 \pm 3.39$ & $27.5 \pm 3.81$ & \multirow[t]{2}{*}{0.677} \\
\hline Range & $(19-35)$ & $(18.6-34.6)$ & \\
\hline \multicolumn{4}{|l|}{ Patients with hiatal hernia: $n(\%)^{\mathrm{b}}$} \\
\hline None & $25(34.2)$ & $16(37.2)$ & \multirow[t]{4}{*}{0.516} \\
\hline $1 \mathrm{~cm}$ & $21(28.8)$ & $13(30.2)$ & \\
\hline $2 \mathrm{~cm}$ & $17(23.3)$ & $12(28)$ & \\
\hline $3 \mathrm{~cm}$ & $10(13.7)$ & $2(4.6)$ & \\
\hline \multicolumn{4}{|l|}{ Patients with esophagitis: $n(\%)$} \\
\hline None & $66(88)$ & $40(93)$ & \multirow[t]{3}{*}{0.795} \\
\hline Grade A & $6(8)$ & $2(4.67)$ & \\
\hline Grade B & $3(4)$ & $1(2.33)$ & \\
\hline Heartburn score per HRQL & $26.9 \pm 4.5(20-42)$ & $26 \pm 4.77(20-38)$ & 0.296 \\
\hline Regurgitation score per HRQL & $17.7 \pm 7.38(0-30)$ & $17.7 \pm 4.93(5-27)$ & 0.98 \\
\hline $\begin{array}{l}\text { LES resting pressure per } \\
\text { manometry }(\mathrm{mmHg})\end{array}$ & $13.4 \pm 8.19(0-36.6)$ & $17.9 \pm 11.32(1-39.1)$ & 0.017 \\
\hline Total $\%$ time $\mathrm{pH}$ was $<4$ & $12.4 \pm 6.28(3.5-43.5)$ & $12.3 \pm 5.81(3.6-28.4)$ & 0.902 \\
\hline DeMeester score & $42.7 \pm 21.39(11.9-142.3)$ & $41.6 \pm 19(13.3-102.6)$ & 0.792 \\
\hline SF-36 PCS & $45.2 \pm 9.08(22.6-59.8)$ & $46.9 \pm 8.62(22.2-59.7)$ & 0.316 \\
\hline SF-36 MCS & $50.2 \pm 11.02(16.9-71.7)$ & $51.2 \pm 8.79(28.2-63.6)$ & 0.601 \\
\hline
\end{tabular}

$S F-36$

The general quality-of-life scores (SF-36 physical and mental scores) at 6 months were significantly improved in the Gatekeeper group for physical function ( $p=0.006)$ but not for mental function $(p=0.925)$, with the sham group showing similar results ( $p=0.002$ and 0.325 respectively) (Table 4). No difference in improvement of physical or mental function was observed between the Gatekeeper $(p=0.821)$ and sham $(p=0.347)$ groups at 6 months (Table 4).

\section{PPI consumption}

At baseline, all the patients were taking daily PPIs (dose equipotent or more potent than $20 \mathrm{mg}$ omeprazole or its equivalent). At 6 months, $55 \%$ of the patients in the Gatekeeper group had stopped taking GERD medications, specifically PPIs, H2 blockers, and prokinetics, compared with $23 \%$ in the sham group (Gatekeeper vs sham treatment, $p=0.008$ ).

\section{Discussion}

The use of biocompatible materials as tissue-augmenting agents is an established procedure that has been used for many years in urology and dermatology [16-18]. As an investigational approach, endoscopic bulking technology for GERD dates back to the early 1980s [19, 20]. Lower esophageal sphincter bulking therapies share a common theoretical mechanism of action that involves increasing wall thickness at the gastroesophageal junction and reducing compliance of the LES. The ideal implant should be biologically and chemically inert, nonmigrating, durable, and capable of inducing a negligible foreign body reaction. Of the many injectable products available, Enteryx [7], Gatekeeper [8], and plexiglass beads [9] have been investigated for GERD.

Initial studies with a limited number of patients showed that the Gatekeeper procedure significantly decreased heartburn, improved quality of life, decreased 24-h pH-metry scores, and decreased medication usage [21]. The success rate for implantation was $93 \%$, whereas the 


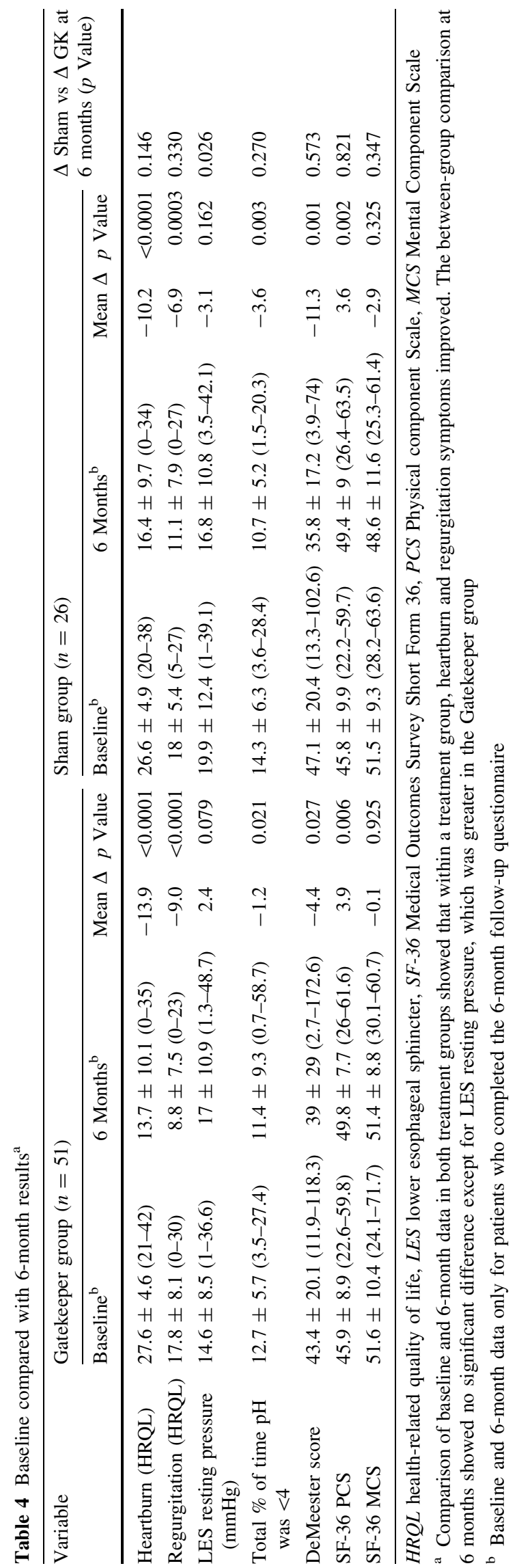

procedural success rate was reported at $98.7 \%$ [22]. After completion of a 6-month pilot study [8] with favorable results, a European multicenter study was initiated [23]. The average number of prostheses implanted was 4.3 (range, 2-6). The final results showed significant improvement in quality-of-life scores (HRQL score from 24 to 5), $\mathrm{pH}$ parameters ( $\%$ of $24 \mathrm{~h}$ that $\mathrm{pH}$ was $<4 ; 9.1 \%$ decreased to $6.1 \%$ ), and LES pressure $(8.8 \mathrm{mmHg}$ improved to $13.8 \mathrm{mmHg}$ ) at 6 months. The prostheses retention rate was $73 \%$ at 6 months. Of 40 patients, $2(5 \%)$ experienced severe complications including esophageal perforation caused by overtube placement and severe postprandial nausea leading to endoscopic removal of the prostheses at 3 weeks.

Based on the relative efficacy and safety noted, a larger, randomized, sham-controlled, single-blinded, multicenter study of the Gatekeeper Reflux Repair System was initiated. Although improvements in many parameters compared with baseline were seen at 6 months in the sham and active treatment groups, and although such improvements persisted for 12 months in the active treatment group (with no sham data available for comparison), the active treatment was not superior to sham treatment with regard to the efficacy of management of most GERD parameters. Such limited efficacy compared with the sham procedure resulted in early study termination.

One significant positive outcome for the active treatment over that for the sham treatment was seen for medication use. At 6 months, $55 \%$ of the patients in the active treatment group were able to discontinue their PPIs completely, compared with only $23 \%$ of the patients in the sham group $(p=0.008)$. The quality-of-life scores (SF-36 and HRQL) and 24-h pH monitoring were slightly improved in both treatment groups. No significant improvement in LES pressure was observed at the 6-month follow-up assessment in the active treatment group. The negative results for the objective response parameters in the active treatment group contrasted with the significant reduction of heartburn and regurgitation symptoms in the active treatment and sham groups.

Some of the subjective and objective parameters in the sham group showed statistically significant improvements. Such a large sham effect may have been due to patient education, with better management of GERD-provoking behavior and continued use of permitted antacids throughout the study. Additionally, the active and sham patients completed the GERD-HRQL questionnaires after cessation of medication therapy for only 7 days. This may not have been adequate to "reactivate" GERD fully in the sham group. Other studies on the endoscopic treatment of GERD have seen a favorable therapeutic response in the sham group in [24-27]. Studies longer than 6 months may be needed to decrease the sham effect. 
Table 5 Improvement in the Gatekeeper group at 12 months $^{\mathrm{a}}$

\begin{tabular}{|c|c|c|c|c|c|}
\hline Variable & $N$ & Baseline $^{\mathrm{b}}$ & 12 Months $^{\mathrm{b}}$ & Mean change, STD & $p$ Value \\
\hline Heartburn (HRQL) & 22 & $27.7 \pm 4.8(21-37)$ & $14.8 \pm 10.6(1-34)$ & $-12.9,10.5$ & $<0.0001$ \\
\hline Regurgitation (HRQL) & 22 & $17.1 \pm 9.2(0-29)$ & $8.7 \pm 8.8(0-24)$ & $-8.4,9.2$ & 0.0003 \\
\hline LES resting pressure $(\mathrm{mmHg})$ & 20 & $11.9 \pm 7.2(1-28.8)$ & $14.5 \pm 9.1(4.3-33.4)$ & $2.6,9.8$ & 0.246 \\
\hline Total $\%$ of time $\mathrm{pH}$ was $<4$ & 20 & $14.1 \pm 8.8(4.5-43.5)$ & $13.3 \pm 17(2.3-83)$ & $-0.8,18.6$ & 0.114 \\
\hline DeMeester & 20 & $48.9 \pm 28(15-142.3)$ & $36.4 \pm 19.9(7.1-89.8)$ & $-12.4,33$ & 0.048 \\
\hline SF-36 PCS & 21 & $44.6 \pm 9(27.3-59.8)$ & $50.2 \pm 9.2(26.5-61.3)$ & $5.6,10.5$ & 0.025 \\
\hline SF-36 MCS & 21 & $54.3 \pm 9.7(39-71.7)$ & $53.1 \pm 6.2(41.1-63.6)$ & $-1.2,8.2$ & 0.502 \\
\hline
\end{tabular}

$H R Q L$ health-related quality of life, LES lower esophageal sphincter, SF-36 Medical Outcomes Survey Short Form 36, PCS Physical Component Scale, MCS Mental Component Scale

a At 12 months, the improvement in the Gatekeeper group continued to be significant. Because the sham group either crossed over to the Gatekeeper group or exited the study at 6 months, there was no sham comparison at 12 months

${ }^{\mathrm{b}}$ Baseline and 12-month data only for Gatekeeper group patients who completed the 12-month follow-up questionnaire

Preliminary animal studies and pilot human studies $[8$, 21-23] had suggested that the current Gatekeeper device would be effective. The optimal number of prostheses, the site of placement (above or below the squamocolumnar junction), and the size of the implant were not known. No human studies comparing various doses had been done. A factor of "low dosing" in this study was the prostheses retention rate of only $73 \%$ at 6 months and $63 \%$ at 12 months. Mucosal ulceration over the prostheses occurred in $32.3 \%$ of the patients. This likely had a significant effect on the prostheses retention rate, accordingly reducing the treatment dose. Also, some technical issues of implantation affected implantation success. The cardia is acutely angulated at the angle of His. This made implant delivery less successful in this quadrant because tissue was more difficult to retain in the suction grove of the overtube.

It was uncertain whether respiratory movement affected implantation technique. Visualization through the overtube was required for implantation and was technically difficult. Blood and secretions were unquantitated compromising factors. These features may have presented significant obstacles to accurate injection or implantation of the prostheses. After implantation, visualization of the prostheses was difficult both endoscopically, due to the various implantation depths, and on X-ray, due to the similarity of prostheses to normal tissue.

This study also highlights the importance of careful, well-designed, randomized, controlled trials (RCT) such as the current trial for evaluating new medical devices. These trials are of major importance in assessing the balance of benefits and harm. Evidence that emphasizes only benefits likely will lead to biased conclusions. The control group in this type of RCT allows for monitoring of treatment effects and adverse events associated with the intervention throughout the trial. A challenge in studying endoscopic interventions for GERD patients is ensuring the safety of the participants.

In summary, this sham-controlled trial of endoscopic implantation of Gatekeeper prostheses for GERD showed that this procedure is associated with serious but infrequent complications and improves GERD symptoms, quality of life, and drug use for GERD patients at 6 months, with this trend persisting for at least 12 months. The sham group showed many similar improvements, however. The improvements in esophageal functions (esophageal acid exposure and LES pressure) in the active treatment group were minimal and not clinically meaningful. Overall, no statistically or clinically significant differences in outcomes were observed between the treatment group and the control group at 6 months compared with baseline (Table 4). For this reason, the study was terminated early.

The concept of endoluminal treatment for GERD continues to be appealing because it focuses on gastroesophageal reflux control and not just acid secretory control [28, 29]. Currently effective medical and surgical therapies for GERD create a relatively high standard for new endoscopic therapies. To date, the major obstacles against their wider spread use include limited to moderate efficacy for most devices, lack of good reimbursement codes in the United States, serious complications (although less frequent than for fundoplication), and insufficient funding and support for research to develop new technologies to treat GERD. More work is needed before these approaches can be considered a standard of care for GERD.

Additional studies are required to determine whether the effectiveness of these techniques can be improved either by increasing the therapy dose (using more sutures or implanted material per session, better placement of prostheses, or multiple sessions) or by identifying diagnostic parameters that better select patients likely to be 
responders. Further refinement, development, and differentiation of relatively simple, therapeutically effective, cost-effective methods are anticipated.

Disclosures Paul Fockens, Lawrence Cohen, Steven Edmundowicz, Kenneth Binmoeller, Richard Rothstein, Daniel Smith, Edward Lin, Nicholas Nickl, Bergein Overholt, Peter Kahrilas, Nimish Vakil, and Glen A. Lehman have no conflicts of interest or financial ties to disclose.

Open Access This article is distributed under the terms of the Creative Commons Attribution Noncommercial License which permits any noncommercial use, distribution, and reproduction in any medium, provided the original author(s) and source are credited.

\section{References}

1. El-Serag HB, Petersen NJ, Carter J, Graham DY, Richardson P, Genta RM, Rabeneck L (2004) Gastroesophageal reflux among different racial groups in the United States. Gastroenterology 126:1692-1699

2. Richter JE (2007) Gastrooesophageal reflux disease. Best Pract Res Clin Gastroenterol 21:609-613

3. Boeckxstaens GE (2007) Review article: the pathophysiology of gastro-oesophageal reflux disease. Aliment Pharmacol Ther 26:149-160

4. Bittinger M, Messmann H (2007) Gastroesophageal reflux disease and Barrett's esophagus. Endoscopy 39:118-123

5. Coron E, Hatlebakk J, Galmiche J (2007) Medical therapy of gastroesophageal reflux disease. Curr Opin Gastroenterol 23:434439

6. Pessaux P, Arnaud J, Delattre J, Meyer C, Baulieux J, Mosnier H (2005) Laparoscopic antireflux surgery: five-year results and beyond in 1,340 patients. Arch Surg 140:946-951

7. Johnson DA, Ganz R, Aisenberg J, Cohen LB, Deviere J, Foly TR, Haber GB, Peter LH, Lehman GA (2003) Endoscopic implantation of enteryx for treatment of GERD: 12-month results of a prospective, multicenter trial. Am J Gastroenterol 98:1921 1921

8. Fockens P (2003) Gatekeeper reflux repair system: technique, preclinical, and clinical experience. Gastrointest Endosc Clin N Am 13:179-189

9. Feretis C, Benakis P, Dimopoulos C, Dailianas A, Filalithis P, Stamou KM, Manouras A, Apostolidis N (2001) Endoscopic implantation of Plexiglas (PMMA) microspheres for the treatment of GERD. Gastrointest Endosc 53:423-426

10. Triadafilopoulos G (2003) Clinical experience with the Stretta procedure. Gastrointest Endosc Clin N Am 13:147-155

11. Pleskow D, Rothstein R, Lo S, Hawes R, Kozarek R, Haber G, Gostout C, Lembo A (2004) Endoscopic full-thickness plication for the treatment of GERD: a multicenter trial. Gastrointest Endosc 59:163-171

12. Cadière GB, Rajan A, Rqibate M, Germay O, Dapri G, Himpens J, Gawlicka AK (2006) Endoluminal fundoplication (ELF): evolution of EsophyX, a new surgical device for transoral surgery. Minim Invasive Ther Allied Technol 15:348-355

13. Sud R, Puri R, Chung S, Cotton P (2006) The His-Wiz antireflux procedure results in symptomatic and $\mathrm{pH}$ improvement at 1 year of follow-up. Gastrointest Endosc 63:AB131
14. Bortolotti M (2006) A novel antireflux device based on magnets. J Biomech 39:564-567

15. Ganz R, Gostout C, Berg T (2006) Use of an artificial sphincter for the treatment of GERD-preliminary study. Gastrointest Endosc 63:AB79

16. Dastoor SF, Misch CE, Wang HL (2007) Dermal fillers for facial soft tissue augmentation. J Oral Implantol 33:191-204

17. Godbole P, Bryant R, Mackinnon AE, Roberts JP (2003) Endourethral injection of bulking agents for urinary incontinence in children. BJU Int 91:536-539

18. Zimmern PE (2002) A new injectable bulking agent for treatment of stress urinary incontinence. Curr Urol Rep 3:400

19. O'Connor KW, Madison ST, Smith DJ, Ransburg RC, Lehman GA (1984) An experimental endoscopic technique for reversing gastroesophageal reflux in dogs by injecting inert material in the distal esophagus. Gastrointest Endosc 30:275-280

20. O'Connor KW, Lehman GA (1988) Endoscopic placement of collagen at the lower esophageal sphincter to inhibit gastroesophageal reflux: a pilot study of 10 medically intractable patients. Gastrointest Endosc 34:106-112

21. Fockens P, Bruno M, Hirsch D, Lei A, Boeckxstaens G, Tytgat GN (2002) Endoscopic augmentation of the lower esophageal sphincter: pilot study of the Gatekeeper reflux repair system in patients with GERD. Gastrointest Endosc 55:AB257

22. Fockens P, Boeckxstaens G, Gabbrielli A, Costamagna G, Hattlebakk J, Odegaard S, Allescher HD, Roesch T, Muehldorffer S, Bastid J, Rey F, Bastid C (2003) Endoscopic augmentation of the lower esophageal sphincter for GERD: final results of a European multicenter study of the Gatekeeper system. Gastointest Endosc 59:AB242

23. Fockens P, Costamagna G, Gabrielli A, Odegaard S, Hattlebakk J, Rhodes M, Allescher HD, Roesch T (2002) Endoscopic augmentation of the lower esophageal sphincter (LES) for the treatment of GERD: multicenter study of the gatekeeper reflux repair system. Gastrointest Endosc 55:AB89

24. Corley DA, Katz P, Wo JM, Stefan A, Patti M, Rothstein R, Edmundowicz S, Kline M, Mason R, Wolfe MM (2003) Improvement of gastroesophageal reflux symptoms after radiofrequency energy: a randomized, sham-controlled trial. Gastroenterology 125:668-676

25. Deviere J, Costamagna G, Neuhaus H, Voderholzer W, Louis H, Tringali A, Marchese M, Fiedler T, Darb-Esfahani P, Schumacher B (2005) Nonresorbable copolymer implantation for gastroesophageal reflux disease: a randomized sham-controlled multicenter trial. Gastroenterology 128:532-540

26. Montgomery M, Håkanson $\mathrm{B}$, Ljungqvist $\mathrm{O}$, Ahlman $\mathrm{B}$, Thorell A (2006) Twelve months' follow-up after treatment with the EndoCinch endoscopic technique for gastro-oesophageal reflux disease: a randomized, placebo-controlled study. Scand J Gastroenterol 41:1382-1389

27. Rothstein R, Filipi CJ, Caca K, Pruitt R, Mergener K, Torquati A, Haber G, Chen Y, Chang K, Wong D, Deviere J, Pleskow D, Lightdale C, Ades A, Kozarek R, Richards W, Lembo A (2006) Endoscopic full-thickness plication for the treatment of gastroesophageal reflux disease: a randomized, sham-controlled trial. Gastroenterology 131:704-712

28. Pace F, Costamagna G, Penagini R, Repici A, Annese V (2007) Review article: endoscopic antireflux procedures: an unfulfilled promise? Aliment Pharmacol Ther 27(5):375-384

29. Pleskow D, Rothstein R, Lo S, Hawes R, Kozarek R, Haber G, Gostout C, Lembo A (2005) Endoscopic full-thickness plication for GERD: 12-month multicenter study results. Gastrointest Endosc 61:643-649 